\title{
Exploring Environmental Policy in the Hotel Sector
}

\author{
Chieh-Heng Ko, Wen-Hsiang Yuan \\ Department of Hospitality Management, College of Tourism and Hospitality, Da-Yeh University, Taiwan \\ Email: chko@mail.dyu.edu.tw, kevin106@mail.dyu.edu.tw
}

How to cite this paper: Ko, C.-H. and Yuan, W.-H. (2019) Exploring Environmental Policy in the Hotel Sector. Open Access Library Journal, 6: e5835.

https://doi.org/10.4236/oalib.1105835

Received: October 8, 2019

Accepted: October 25, 2019

Published: October 28, 2019

Copyright (C) 2019 by author(s) and Open Access Library Inc.

This work is licensed under the Creative Commons Attribution International License (CC BY 4.0).

http://creativecommons.org/licenses/by/4.0/

(c) (7) Open Access

\begin{abstract}
This study illustrates alternative "green" strategies to indicate possible reactions of the hotel sector to the environmental issue and the extent of the "greening" process on the control system. Questionnaire survey was used to discuss the environmental standing of hotel and the control system. Analysis is based on comparison of hotel managers operating with an environmental policy and those managers operating without. Tentative conclusions indicated that although a number of companies have adopted an environmental policy, in general, the hotel sector is not taking a proactive approach to environmental concerns.
\end{abstract}

\section{Subject Areas}

Economics

\section{Keywords}

Green Strategies, Control System, Environmental Policy, Hotel

\section{Introduction}

The "greening" of industry is an issue which has been increasing in importance since the late 1980s [1] [2]. Although the chemical and oil industries were initially the focus of attention for environmentalists due to the visible nature of their environmental impact, the service industries will find themselves under scrutiny [3] [4]. Although they are perhaps less visible in their environmental impact, it is increasingly being recognized that they too have a responsibility to reduce what impact they do have. The hospitality industry will no longer be able to ignore its environmental responsibilities as it will have to respond to a number of pressures. For example, the "green tourist" will demand "green" accommodation [5]; legislation with regard to the disposal of waste has implications 
for the hospitality industry; and the continued increase in energy costs will necessitate reductions in usage.

In this article the reaction of the hotel sector to the environmental issue is considered from a strategic control perspective. In particular, the link between the control system and the environmental status of the hotel group is explored. Analysis is made of the results of a questionnaire survey which was undertaken during late 2018. The environmental issue and the accounting control system operating within hotel companies are considered from the perspective of the hotel general manager. Only tentative conclusions can be drawn as regards the hotel sector and its response to the environmental issue on the basis of this study but, if representative, then there is some cause for concern.

\section{Literature Review}

\subsection{Environmental Issue within the Hotel Sector}

Taiwanese hotel sector would appear to accept that it does have an impact on the environment [6]. This is not only confirmed by exploratory research but also through the formation of the International Hotels Environmental Initiative (IHEI). The IHEI has published an environmental manual Environmental Management for Hotels: the Industry Guide to Best Practice which is aimed at hotel general managers. As an alternative to the manual the IHEI has also produced an action pack designed for the small and independent hotel operator. A number of hotel groups have also separately developed their own environmental programmers and initiatives. These include newsletters on "green" issues, environmental committees and "green" bedrooms.

It is evident from the literature that cost benefits can be achieved by operating a more "environmentally friendly" hotel. However, anecdotal evidence would suggest that of more concern to the hotelier is the impact of environmental initiatives on the perceived quality and service of the hotel. One solution to this problem would be education of guests about environmental factors and allowing them the opportunity of choosing the "environmental", option. A further concern of the hotelier is that "environmentally friendly" alternatives are perceived as less efficient than the normally-used products [7]. This problem should become less apparent as suppliers recognize the demand for satisfactory "green" products and provide adequate alternatives. The general manager in the hotel sector does appear to recognize that the hospitality industry does have an impact on the environment [6]. However he/she would appear to be restricted in introducing environmental improvements in the hotel unless a cost saving or other tangible benefit is identified [6].

\subsection{Control System}

The control system is an important part of the structure of the organization [8], and of the strategy implementation process [9] [10]. The control system provides the means for senior management of the hotel group to monitor the per- 
formance of its general managers and motivate these managers to achieve the organizations' objectives [9] [11]. The control system may be regarded as a function of both the strategy [12] [13] and the structure of the organization [9].

The control system may include a number of components such as organizational culture [8], supervisory visits [14], standardized procedures and manuals [14], accounting and non-accounting information [14] [15], and the reward system [8] [9] [14] [15]. It is not simply the use of a particular package of control techniques which defines the control system but rather the individual weighting placed on each of the control components [10] [14]. The individual components of the control system should match the structure [8]. If there is conflict between individual controls then a dysfunctional effect may be the outcome [16]. Each component or sub-unit of the control system should be consistent with one another [8] and should persuade the manager to act in the best interests of the organization [9].

Brown [6] has suggested that the most important accounting controls used within the hotel sector in assessing the performance of the general manager were achievement of budget and profits. The only non-accounting information on which the general manager would appear to be judged by his head office is customer complaints. In another study of hotel managers, Umbreit and Eder [17] looked at the link between behavior and outcome measurement. They found that there was "...a general lack of consensus across hotel firms in defining managerial effectiveness" [17]. The reasons identified for the difference in outcome measurement may relate to the market position of the company, strategy, financial position, management style and age of the company [18].

There is no evidence as yet, of the hotel sector recognizing environmental initiatives in the control system [6] [19]. This would appear to be one of the factors preventing the general manager introducing environmental improvements. Research in the USA has confirmed that the majority of managers would appear to be hindered because of the nature of the control system in which the budgeted results do not recognize environmental initiatives [19].

\subsection{Environmental Strategy}

A number of generic strategic archetypes [12] [20] [21] have been developed as well as specific lodging industry strategies [22]. However, the relevance of either generic strategies or hotel-specific strategies in relation to environmental issues should be in doubt. As has been stated [23] managers "may still be operating with the old world mental models that do not give sufficient value to the environment". Strategies will need to be developed where the environment is viewed to be as important as traditional strategic requirements, such as profitability, growth, etc. In other words, the environment cannot be treated as an "add-on to the other corporate policies" [24], but should become a strategic direction in itself.

If the strategic reaction of senior management is to simply view the environmental issue as a policy decision, then any necessary changes are slotted into the 
existing structure of the organization. Alternatively the environmental issue may be viewed as of such importance that a change in strategy is required. This will involve more fundamental changes as the existing structure of the organization will be required to adapt to the new environmental strategy.

An organization's response to environmental concerns may be described as either reactive or proactive [25]. A reactive response organization is one which "follows the pace of change dictated by social, scientific and the legislative agenda on the environment" [25]. A proactive response organization is one which is responding through "management systems which can be verified, to challenge existing management conventions and to encourage organizational change" [25]. A proactive organization therefore has identified environmental concerns as a strategic issue and is adapting both its structure and control system to accommodate the new strategy. This environmental strategy will involve the company in additional costs with the extent of the expenditure depending on the level of environmental excellence the organization wishes to achieve [25].

Roome [25] describes two environmental response strategies which are proactive-a "compliance plus" strategy and "excellence" strategy. The main differences between these two strategies are the scale of the organization's environmental ethic and the level of organizational change to support a "corporate environmental ethic" [25].

Similarly Sadgrove [2] identifies two proactive responses to the environmental issue that an organization may take. However, the main difference identified between the responses is cost. The high cost option gives the company a high profile to the extent that it may become a leading edge or best practice company. The low cost option also allows the company to have a green image but with no cost, or low costs involved.

Once the organization adopts a proactive response to the environmental issue then changes to its strategy should be matched by changes to the control system. This will involve changes to the individual components within the control system. Control through the reporting requirement of financial information should be extended to allow for environmental reporting. This may involve a move away from performance appraisal on purely financial criteria to the use of non-financial criteria. Environmental reporting should become part of the reporting requirements of the managers [1] [2] and of the organization [1]. Therefore the environmental performance of the hotel should become an integral part of the appraisal system [26] of the general manager.

\section{Methodology}

It was decided that a questionnaire survey of general managers would be appropriate in order to try to draw some tentative conclusions about the hotel sector's reaction to the environmental issue. A sample of managers from "large" and "medium" hotel groups was compiled from the group's directory. The first stratum of "large" group managers consisted of 116 managers chosen at random 
from hotel groups. The second stratum of "medium" group hotels consisted of a sample of 84 managers chosen at random from hotel groups. The third stratum of "independent" managers was chosen at random from both the Taiwan Tourist Board. Table 1 shows an analysis of the responses.

\section{Results}

The existence of an environmental policy would indicate an awareness of environmental concerns though not the importance placed on the issue. Forty-three of the respondents stated that they did have an environmental policy operating in their hotel, as compared with 60 who did not. The research focused on the general manager and his reporting requirements therefore a number of owner/managers were deleted. The analysis was therefore on the basis of 33 managers operating "with an environmental policy" and 54 managers operating with "no policy”.

\subsection{Environmental Awareness}

The hotel's general manager is responsible for implementing the company's environmental policy at the unit level. Therefore he should be more able to recognize the environmental issues as they affect his hotel than a manager who is operating without an environmental policy. It was hypothesized that the "with policy" manager will be more environmentally aware than the "no policy" manager. A $z$ score of +2.33 (one-tailed test) would indicate a significant difference at 1 per cent level of significance.

As shown in Table 2 the level of awareness of the environmental impact of the hotel was not rated particularly high by either group of managers. However, the managers rated themselves as the most environmentally aware of all the hotel's stakeholders. The "with policy" managers perceived themselves as significantly more environmentally aware than the "no policy" managers, and also rated their employees, head office and shareholders as significantly more aware than the "no policy" managers. However, given the low level of perceived awareness, neither group of managers seems to be particularly environmentally aware. Generally there would appear to be little environmental pressure being exerted by the stakeholders of the hotel. The managers did not view care for the environment

Table 1. Summary of responses to questionnaire.

\begin{tabular}{|c|c|c|c|c|c|}
\hline & & \multicolumn{2}{|c|}{ Size of group } & \multicolumn{2}{|c|}{ Environmental policy } \\
\hline & \multicolumn{5}{|l|}{ Responses } \\
\hline Large hotel groups & $52(41.9)$ & 25 & 27 & 20 & 30 \\
\hline Medium hotel groups & $26(34.7)$ & 21 & 5 & 11 & 15 \\
\hline Independents & $28(28.6)$ & 28 & 0 & 12 & 15 \\
\hline Total & $106(35.7)$ & 74 & 32 & 43 & 60 \\
\hline
\end{tabular}

Note: Figures in parentheses are percentages. 
Table 2. General manager's perception of importance placed on control criteria.

\begin{tabular}{cccccc}
\hline & \multicolumn{2}{c}{ With policy } & \multicolumn{2}{c}{ No policy } & \\
\hline & $\begin{array}{c}\text { Mean Standard } \\
\text { deviation }\end{array}$ & $\begin{array}{c}\text { Mean Standard } \\
\text { deviation }\end{array}$ & z score \\
\hline Achievement of budget & 4.57 & 0.60 & 4.66 & 0.61 & -0.63 \\
Maintenance/improvement in profitability & 4.67 & 0.53 & 4.75 & 0.48 & -0.73 \\
Report on customer complaints & 4.55 & 0.74 & 4.06 & 0.90 & 2.74 \\
Adherence to operations manual & 3.64 & 1.06 & 3.21 & 1.06 & 1.80 \\
Report on staff turnover & 3.54 & 1.06 & 2.51 & 1.00 & 3.27 \\
Report on external factors affecting the business & 3.79 & 0.84 & 2.92 & 1.05 & 4.17 \\
Report on internal initiatives being taken & 4.12 & 0.84 & 3.71 & 0.91 & 2.12 \\
Environmental reporting & 3.33 & 0.97 & 2.56 & 1.13 & 3.35 \\
Achieving environmental targets & 3.19 & 1.13 & 2.29 & 1.18 & 3.48 \\
\hline
\end{tabular}

Key: 5 = very important, $1=$ not at all important.

as particularly important when considering the various criteria which may be used to justify changes in the hotel [6].

\subsection{Control System}

The manager's response to the environmental issue could be influenced by the nature of the control system. For example, the requirement to achieve his budgeted targets or profitability level could restrict his ability to introduce environmental initiatives which did not achieve an improvement in his results. If a company has adopted an environmental policy then the environmental issue has been recognized and the company should have adapted its control system to allow for this. Environmental reporting should become part of the reporting requirements of the manager. It was hypothesized that there will be a difference in the control system between the "with policy" and "no policy" companies. The individual components of the control system were analyzed using a z-score calculation to indicate any significant difference between the two groups of managers. For the purposes of the analysis a $z$ score of $+/-2.58$ (two-tailed test) would indicate a significant difference at the 1 per cent level of significance. Table 3 shows the results of the analysis of the managers' reporting requirements.

As previously identified by Brown [6] the three most important forms of reporting in the hotel sector are achievement of budget, maintenance of profitability and reporting of customer complaints. However, the "with policy" managers perceive a number of other reporting requirements as significantly more important to their head office than the "no policy" managers. In particular there are significant differences between the two groups in the reporting of customer complaints, staff turnover, external factors, environmental reporting and environmental target achievement. Therefore, although both financial reporting and customer complaints remain important to both groups of managers, the "with 
Table 3. Stakeholders' awareness of the environmental impact of the hotel as perceived by the general manager.

\begin{tabular}{ccccccccc}
\hline & \multicolumn{2}{c}{ Overall } & \multicolumn{2}{c}{ With policy } & \multicolumn{3}{c}{ No policy } \\
\cline { 2 - 8 } & Mean & $\begin{array}{c}\text { Standard } \\
\text { deviation }\end{array}$ & Mean & $\begin{array}{c}\text { Standard } \\
\text { deviation }\end{array}$ & Mean & $\begin{array}{c}\text { Standard } \\
\text { deviation }\end{array}$ & z score \\
\hline Yourself & 3.70 & 1.11 & 4.09 & 0.96 & 3.32 & 1.06 & 3.46 \\
Employees & 2.86 & 1.00 & 3.39 & 0.89 & 2.49 & 0.92 & 4.52 \\
Guests & 2.38 & 0.94 & 2.40 & 0.90 & 2.19 & 0.91 & 1.08 \\
Local community & 2.61 & 0.97 & 2.69 & 1.01 & 2.52 & 0.99 & 0.75 \\
Head office & 2.89 & 1.13 & 3.61 & 0.97 & 2.40 & 0.99 & 5.38 \\
Shareholders & 2.32 & 1.16 & 2.71 & 1.19 & 1.98 & 0.98 & 2.73 \\
Bank & 1.86 & 0.95 & 1.96 & 0.94 & 1.65 & 0.84 & 1.44 \\
Suppliers & 2.24 & 1.06 & 2.35 & 1.03 & 2.04 & 0.98 & 1.36 \\
Loan creditors & 1.81 & 1.04 & 1.76 & 0.81 & 1.62 & 0.87 & 0.67 \\
\hline
\end{tabular}

Key: $5=$ very important, $1=$ not at all important.

policy" managers do seem to be more aware that non-financial data, including environmental information, may be part of their performance appraisal.

Two other components of the control system on which the managers were questioned were supervisory visits and the reward system. Although significant differences were identified between the two groups, specifically in promotion within the group and job security, these differences are more likely to be due to factors other than the control system or the adoption of an environmental policy. For example, the size of the hotel group or the financial situation of the hotel could be a factor.

\subsection{Environmental Strategy}

Hotel companies are faced with a number of strategic issues, one of which is environmental concern. However not all hotel companies will recognize environmental concern to be of sufficient importance for it to be considered at all, let alone in a strategic context. In order to gauge if environmental concern is perceived to be of strategic importance to the hotel company the manager was asked to consider a number of strategic issues and to rate the importance to his hotel group. The results are shown in Table 4.

It was hypothesized that the "with policy" manager would rate the strategic importance of environmental concern more highly than the "no policy" manager. A $z$ score of +2.33 (one-tailed test) would indicate a significant difference at the 1 per cent level of significance. Statistically then there is a significant difference between the two groups of managers in the perceived importance of environmental concern as a strategic issue. The "with policy" managers did rate environmental concerns as more important than the "no policy" managers. However, the level of importance of the "with policy" managers was only marginally 
Table 4. Perceived importance of strategic issues to manager's hotel.

\begin{tabular}{llllll}
\hline & \multicolumn{2}{c}{ With policy } & \multicolumn{2}{c}{ No policy } & \\
\cline { 2 - 6 } & \multicolumn{2}{c}{$\begin{array}{c}\text { Mean Standard } \\
\text { deviation }\end{array}$} & $\begin{array}{c}\text { Mean Standard } \\
\text { deviation }\end{array}$ & z score \\
\hline European/worldwide expansion & 3.76 & 1.36 & 2.52 & 1.35 & 3.95 \\
\hline Financial requirements: & & & & & \\
\hline Share price, dividend, etc. & 4.12 & 0.75 & 3.64 & 1.43 & 1.82 \\
Reduction in borrowings & 4.26 & 0.75 & 4.09 & 1.14 & 0.78 \\
Maintenance of market share & 4.57 & 0.73 & 4.57 & 0.69 & 0.02 \\
Environmental concern & 3.41 & 0.85 & 2.82 & 0.78 & 3.07 \\
Improved quality of service to customer & 4.66 & 0.54 & 4.60 & 0.59 & 0.40 \\
Development of information technology & 4.03 & 0.89 & 3.69 & 0.82 & 1.70 \\
\hline Expansion through: & & & & & \\
\hline Internal growth & 4.33 & 0.86 & 4.00 & 0.93 & 0.58 \\
Acquisition & 3.77 & 1.12 & 3.58 & 1.15 & 0.71 \\
Management contract & 3.79 & 1.34 & 3.11 & 1.25 & 2.18 \\
Franchising & 2.59 & 1.42 & 1.80 & 1.05 & 2.54 \\
Sustainability of the business & 4.62 & 0.61 & 4.44 & 0.66 & 1.22 \\
Maintenance of average room rate & 4.14 & 0.77 & 4.32 & 0.95 & -0.94 \\
\hline Key: 5 very imporyyyyyyyy & & & & &
\end{tabular}

Key: $5=$ very important, $1=$ not at all important.

important with a mean of 3.41 (a mean of 3 would indicate neither important nor unimportant).

\section{Discussion and Conclusions}

The general manager of a hotel is subject to a control system, part of which may include financial and non-financial reporting. Financial reporting is perceived as important to the manager's head office regardless of the environmental standing of the hotel company. However non-financial reporting controls do appear to be more important to the senior management of a hotel company operating with an environmental policy. This difference would not appear to be due to the reporting of environmental data, however, as this particular form of reporting is not rated particularly high in importance by the "with policy" managers. Possible explanations for the difference in the importance of reporting non-financial data between the "with policy" and the "no policy" managers could be a different control culture within the hotel group or a different emphasis on the individual components of the control system.

The "with policy" manager perceives the stakeholders of the hotel (including himself) as more environmentally aware than his "no policy" counterpart. However, the level of awareness is disappointing. The adoption of an environmental policy should educate managers to be more environmentally aware; however, it 
would appear that there is a long way to go in this process.

The "with policy" manager perceives the strategic importance of the environmental issue more highly than the "no policy" manager. This is to be expected because the hotel company operating with an environmental policy has shown itself to be more aware of the environmental issue and its importance. The manager is not under pressure from any of the stakeholders to improve the hotel's environmental standing and he himself does not view the issue as particularly important. Both groups of managers did agree that they had the opportunity to influence the strategy of the company. However, in view of the lack of pressure from stakeholders, the extent of his influence on his head office to introduce environmental concern as a strategic issue will be negligible.

Environmental concern has resulted in a number of hotel companies adopting an environmental policy. However, it would appear that those hotel companies operating with an environmental policy have not incorporated environmental reporting in their control system to any great extent. Companies taking a proactive response to environmental concerns should recognize environmental issues at all levels of the organization, including the control system. It would appear therefore that the hotel sector is not as yet taking a proactive approach to environmental concern.

Until environmental concern is recognized as a strategic issue and the control system, which includes financial reporting and the reward system, is adapted; then the response will remain that of a "green" stratagem.

\section{Conflicts of Interest}

The authors declare no conflicts of interest regarding the publication of this paper.

\section{References}

[1] Gray, R., Bebbington, J. and Walters, D. (1993) Accounting for the Environment. Paul Chap-Man Publishing, London.

[2] Sadgrove, K. (1992) The Green Manager's Handbook. Gower Publishing, Aldershot.

[3] Elkington, J. (1990) The Environmental Audit: A Green Filter for Companies Policies, Plants, Processes and Products. Sustainability/WWF, London.

[4] Elkington, J., Knight, P. and Hailes, J. (1991) The Green Business Guide. Victor Gollancz, London.

[5] Elkington, J. and Hailes, J. (1992) Holidays That Don't Cost the Earth. Victor Gollancz, London.

[6] Brown, M. (1994) Environmental Auditing and the Hotel Industry: An Accountant's Perspective. In: Seaton, A.V., Ed., Tourism: The State of the Art, John Wiley \& Sons, Chichester.

[7] Pettit, L. (1992) Going Green Costs Money. Caterer \& Hotelkeeper.

[8] Hill, C.W.L. and Jones, G.R. (1992) Strategic Management. Houghton Mifflin Company, Boston, MA.

[9] Olsen, M.D., Tse, E. and West, J.J. (1992) Strategic Management in the Hospitality 
Industry. Van Nostrand Reinhold, New York.

[10] Simons, R. (1990) The Role of Management Control Systems in Creating Competitive Advantage; New Perspectives. Accounting, Organizations, and Society, 15, 127-143. https://doi.org/10.1016/0361-3682(90)90018-P

[11] Goold, M. and Quinn, J.J. (1990) The Paradox of Strategic Controls. Strategic Management Journal, 11, 43-57. https://doi.org/10.1002/smj.4250110104

[12] Goold, M. and Campbell, A. (1987) Many Best Ways to Make Strategy. Harvard Business Review.

[13] Simons, R. (1987) Accounting Control Systems and Business Strategy: An Empirical Analysis. Accounting, Organizations and Society, 12, 357-374. https://doi.org/10.1016/0361-3682(87)90024-9

[14] Merchant, K.A. (1985) Organizational Controls and Discretionary Program Decision Making: A Field Study. Accounting, Organizations and Society, 10, 67-85. https://doi.org/10.1016/0361-3682(85)90032-7

[15] Hopwood, A. (1974) Accounting and Human Behavior. Haymarket Publishing, London.

[16] Balkin, D.B. and Gomez-Mejia, L.R. (1990) Matching Compensation and Organizational Strategies. Strategic Management Journal, 11, 153-169. https://doi.org/10.1002/smj.4250110207

[17] Umbreit, W.T. and Eder, R.W. (1987) Linking Hotel Manager Behavior with Outcome Measures of Effectiveness. International Journal of Hospitality Management, 6, 139-147. https://doi.org/10.1016/0278-4319(87)90048-X

[18] Geller, A.N. (1985) Tracking the Critical Success Factors for Hotel Companies. (Part 1 of a Series). Cornell Hospitality Quarterly, 25, 76-81. https://doi.org/10.1177/001088048502500414

[19] Zurburg, R., Ruff, D. and Ninemeier, J. (1995) Environmental Action in the United States Lodging Industry. Hospitality \& Tourism Educator, 7, 45-49. https://doi.org/10.1080/23298758.1995.10685658

[20] Miles, R.E., Snow, C.C., Meyer, A.D. and Cole-Man Jr., H.J. (1983) Organizational Strategy, Structure and Process. The Academy of Management Review, 3, 576-562. https://doi.org/10.2307/257544

[21] Porter, M.E. (1980) Competitive Strategy. Free Press, New York.

[22] Schaffer, J.D. (1987) Competitive Strategies in the Lodging Industry. International Journal of Hospitality Management, 6, 33-42. https://doi.org/10.1016/0278-4319(87)90007-7

[23] Stead, W.E. and Stead, J.G. (1992) Management for a Small Planet. Sage Publications, Newbury Park, CA.

[24] Welford, R. (1992) Linking Quality and the Environment: A Strategy for the Implementation of Environmental Management Systems. Business Strategy and the Environment, 1, 25-34. https://doi.org/10.1002/bse.3280010105

[25] Roome, N. (1992) Developing Environmental Management Strategies. Business Strategy and the Environment, 1, 11-24. https://doi.org/10.1002/bse.3280010104

[26] Gray, R. and Collison, D. (1991) The Environmental Audit: Green-Gauge or Whitewash? Managerial Auditing, 6, No. 5. https://doi.org/10.1108/02686909110138934 